\title{
Empirical Evaluation of Metadata for Video Games and Interactive Media
}

\author{
Jin Ha Lee (corresponding author) \\ Information School, University of Washington \\ Mary Gates Hall, Suite 370, Seattle WA 98195 \\ Phone: 206.685.0153, \\ Email: jinhalee@uw.edu \\ Rachel Ivy Clarke \\ Information School, University of Washington \\ Mary Gates Hall, Suite 370, Seattle WA 98195 \\ Phone: 206.685.0153, \\ Email: raclarke@uw.edu \\ Andrew Perti \\ Seattle Interactive Media Museum \\ 305 Harrison St, Seattle WA 98109 \\ Phone: 518.653.5864 \\ Email: andrew.perti@thesimm.org
}

\section{Abstract}

Despite increasing interest in and acknowledgment of the significance of video games, current descriptive practices are not sufficiently robust to support searching, browsing, and other access behaviors from diverse user groups. To address this issue, the Game Metadata Research Group at the University of Washington Information School, in collaboration with the Seattle Interactive Media Museum, worked to create a standardized metadata schema. This metadata schema was empirically evaluated using multiple approaches-collaborative review, schema testing, semistructured user interview, and a large-scale survey. Reviewing and testing the schema revealed issues and challenges in sourcing the metadata for particular elements, determining the level of granularity for data description, and describing digitally distributed games. The findings from user studies suggest that users value various subject and visual metadata, information about how games are related to each other, and data regarding game expansions/alterations such as additional content and networked features. The metadata schema was extensively revised based on the evaluation results, and we present the new element definitions from the revised schema in this article. This work will serve as a platform and catalyst for advances in the design and use of video game metadata.

\section{Introduction}

Video games are of increasing importance to American society as objects of economic stimulus as well as cultural heritage. Because of this increased interest in games for consumer entertainment as well as historical, cultural, and scientific study, many cultural heritage institutions have established collections of video games and related media. The Library of Congress collects, preserves, and offers access to two main types of video games: educational games that support the Library's initiatives and controversial games collected to support legislation related to sex and violence in video games (Owens, 2012). In Great Britain, the National Videogame Archive (NVA) 
focuses on collecting and preserving hardware, original software, design documents, and marketing materials (Newman, 2009). Recently, the British Library began collaborating with the NVA to archive video game-related websites, including screenshots and walkthroughs of games (Crookes, 2012). This related information is valuable to scholars studying games in a social or historical context. Other organizations, such as the Strong National Museum of Play in Rochester, New York, do not collect video games exclusively, but recognize the importance of sharing historical video game information. Their recent exhibit "Atari By Design: From Concept to Creation" used materials on loan from the library and archives at the International Center for the History of Electronic Games, which collects printed materials related to the history of video games and the ways in which they affect how people learn, play, and connect. The exhibit placed design and development materials such as sketches and storyboards alongside original arcade game cabinets to let museum visitors experience the entire process from ideation to gameplay.

These and many other organizations collect, preserve, and circulate video games and interactive media, yet each institution has a unique way of describing them. Public and academic libraries shoehorn video games into their local catalogs, using workarounds in metadata records to differentiate games from other media so that patrons might find them more easily. In the Library of Congress, games are cataloged in the Library's moving images database using metadata designed for motion pictures and sound recordings; however, this solution is still in transition and raises questions about challenges researchers might face trying to find records for games in a database designed primarily for motion pictures that is only available on-site in the Library's reading room. Additionally, current Library of Congress genre headings designed for literature and film are insufficient for video games; they do not adequately describe games in a recognizable way for players or researchers (Owens, 2012). Archives that focus on hardware will also have metadata needs different from those of collections focused on software or print materials. All organizations, regardless of focus, face the challenges of collecting, preserving, and offering access to digitally distributed games, games that have no physical component but exist only in electronic bits accessed through download or streaming from "the cloud." Libraries, archives, and museums need a common, shared metadata standard that covers all aspects of video games - for players, researchers, and curators - that can describe all types of video games, from historic arcade games in cabinets to game apps downloaded on smartphones, in descriptive vocabulary terms that are relevant to games and understandable to users.

To address this issue, the GAMER (GAme MEtadata Research) Group at University of Washington Information School, in partnership with the Seattle Interactive Media Museum (SIMM), has been working on a research project to build a standardized metadata schema and controlled vocabularies for video games since 2011. The objective of our research is to create a robust, mediaspecific metadata schema intended to describe a variety of games, from historical to contemporary, and to serve a variety of use cases to meet the needs of users of the SIMM or other similar cultural heritage organizations. In particular, we seek to answer the following research questions:

1) What kinds of information about video games must be provided to support users' information-seeking activities from their perspective?

2) Is the proposed metadata schema capable of describing a wide variety of games across different genres, formats, platforms, and time periods?

This article reports our efforts to evaluate how well the schema represents and reflects the information needs, behaviors, and language of the user groups for whom it was designed, and whether the current version of the proposed metadata schema is capable of describing all games within the video game domain. 


\section{Relevant Work}

\section{Organization and Preservation of Video Games}

In library and information science, a few projects share similar objectives of improved organization and preservation of video games and interactive media. The Preserving Virtual Worlds project was a collaborative research project conducted by the Rochester Institute of Technology, Stanford University, University of Maryland, and University of Illinois at Urbana-Champaign as part of Preserving Creative America, an initiative of the National Digital Information Infrastructure and Preservation Program at the Library of Congress (McDonough et al., 2010). This project focused on preserving older video games and software, and establishing best practices and strategies for game preservation. It laid preliminary groundwork for basic metadata standards, and the final report specifically calls for future work in establishing relationships and entities and states that the project barely scraped the surface for standardized ontologies in this domain (McDonough et al., 2010). Currently the project is in its second phase, focusing on determining significant properties for educational games. Our project involves a wider range of games, from older games to recent digitally downloadable games and game apps on tablets and smartphones, as well as games for entertainment, and incorporates user behaviors and needs beyond preservation. The motivation for our project also stems from a very practical problem: how best to organize and provide access to SIMM's game collection. Thus, one of our future goals is to create a set of metadata records for a large and diverse game collection.

Stanford University Libraries and the National Institute of Standards and Technology, funded by the National Software Reference Laboratory, have also launched a project on the digital preservation of 15,000 software titles, including games, in the Stanford University Libraries ${ }^{1}$. Their goal is to preserve these titles for use by academic scholars for research purposes. Our project, however, targets a wider range of user personas, representing stakeholders beyond just researchers (Lee, Tennis, Clarke, \& Carpenter, 2013b). Twenty-four user interviews from earlier phases of this research investigated game information needs and search/browse behaviors of real users such as players, parents of players, collectors, developers, and curators. The results directly informed the development of our initial metadata schema and encoding schemes. Stanford University Library, in partnership with the University of Santa Cruz, also recently received funding from Institute of Museum and Library Services (IMLS) to develop a metadata scheme for digital games as well as a system for citing in-game events and game states ${ }^{2}$. We expect that their findings will augment our previous and current research efforts.

Megan Winget led an IMLS-supported video game preservation project centered on studying the creation process and artifacts of the video game industry through observation of and interviews with game developers (Winget \& Sampson, 2011). The project specifically focused on supporting the collection and preservation of massively multiplayer online (MMO) games, whereas our work involves all genres of video games for a variety of platforms (i.e., console, handheld, mobile, PC). Rather than focusing on the creation process of a game, our work emphasizes the user experience and describes the game information that is most relevant to users. This is evidenced by several metadata elements such as mood, visual style, plot, and theme, that describe the content or subject of the games.

Additionally, the International Center for the History of Electronic Games is currently testing the functionality of approximately 7,000 games in their collection and video recording old games, supported by IMLS3. The International Game Developers Association Game Preservation Special Interest Group has also advocated for and published on the importance of preserving video games since 2004 (Newman, 2009). We believe that our research effort will augment the impact of these preservation efforts by greatly enhancing access to collections through robust metadata. 


\section{Evaluation of Metadata Schemas}

Metadata evaluation is a longstanding topic in library and information science, yet perspectives vary on how to perform such evaluation. Most evaluation seeks to identify and improve metadata quality, but few attempt to define concretely what "quality" entails. Without established conceptual and operational definitions, it is difficult, if not impossible, to evaluate metadata quality (Moen, Steward, \& McClure, 1997). In the absence of definitions of quality, scholars and organizations offer different principles that constitute quality metadata. Bruce and Hillmann (2004) compiled seven criteria for metadata quality: completeness, accuracy, provenance, conformance to expectation, logical consistency and coherence, timeliness, and accessibility. National Information Standards Organization (NISO) (2007) identifies "good" metadata as metadata that conforms to community standards; supports interoperability; uses authority control and other content standards; includes clear conditions for and terms of use; supports long-term curation and preservation; and possesses the qualities of authority, authenticity, archivability, persistence, and unique identification. After reviewing multiple studies, Park (2009) notes that completeness, accuracy, and consistency are the most commonly identified criteria for metadata quality. Others do not enumerate lists of criteria but rather summarize quality as "fitness for purpose" (Guy, Powell, \& Day, 2004); that is, does the metadata accomplish the purpose it was designed to achieve? For traditional bibliographic collections, the purpose of metadata is typically to allow users to find, identify, select, and obtain materials of interest (IFLA, 2009), and high-quality metadata must accomplish these goals.

However, methods for measuring metadata quality based on these criteria vary. Many studies focus on evaluation at the metadata-creation stage, with a special focus on how to improve quality at the point of entry. Currier, Barton, O’Beirne, and Ryan (2004) found that inaccurate data entry and inconsistent subject vocabularies affected resource discovery. Simple metadata input tools, such as drop-down menus, can significantly improve consistency and therefore improve metadata quality (Greenberg et al., 2001). To evaluate metadata quality after creation, other methods may be used. One typical method is to assess quality through expert review. However, this raises the question of who qualifies as an expert. For many mature metadata standards, such as those in traditional bibliographic description, longstanding communities such as the Program for Cooperative Cataloging (PCC) and the Online Audiovisual Catalogers (OLAC) have come to consensus over time about definitions of quality (Hillmann, 2008). Such communities also benefit from longevity, because experts develop over time. Unfortunately, nascent metadata standards by their very nature do not have such resources. In any event, regardless of length of participation or amount of experience, a reviewer's expertise may still be considered subjective. Another typical method to evaluate metadata quality after creation is to check for consistency in application among multiple metadata creators. Commonly referred to as "interindexer consistency" because of its origins in indexing studies, this method quantitatively measures the degree of agreement between different indexers indexing the same document (Hughes \& Rafferty, 2011). When used to evaluate metadata creation, it may not be limited to consistency of subject indexing term application but can address the values for any element(s) in a schema. Historical studies show that agreement ranges vary considerably, possibly resulting from a lack of an agreed-upon definition of what constitutes an exact value match and also the use of different measurement calculations (Hughes \& Rafferty, 2011). Although consistency was put forth earlier as a criterion for metadata quality, and interindexer consistency has been looked upon as an indicator of quality (Funk, Reid, \& McGoogan, 1983), consistency may also be detrimental (Bloomfield, 2001). After all, what good is consistently applied metadata if the actual value is incorrect? 
It should be noted that these evaluation techniques - as with most methods of metadata evaluation in general-were designed to evaluate descriptive metadata; that is, recorded descriptive values as opposed to elements of a schema or a schema as a whole. Even less is written about how to evaluate a schema as a holistic entity. One technique is to compare it with other schemas, such as Beak and Olson's (2011) comparative analysis of a standard bibliographic metadata schema with a metadata schema specifically designed for children. Such an analysis was able to highlight missing elements as well as elements directly supporting children's informationseeking behavior, thus increasing access points for children in system implementation. Other methods evaluate the entirety of a metadata schema by implementing it in a functional system and testing it in situ. For example, Shukair, Loutas, Peristeras, and Sklar $\beta$ (2013) developed a federated metadata schema for e-government and sought user feedback on the schema through its deployment via a user interface portal. Although the study reports positive user responses, it is difficult to determine whether the success was due to the schema itself or the design of the user interface through which it was presented. No metadata schema is likely to be used without some sort of interface layer, so the effect of the interface design must always be taken into consideration.

This study evaluates our metadata schema by employing two methods: (a) schema testing by creating sample metadata records of a test collection of video games and (b) user evaluation of the schema through multiple data collection methods. These are discussed further in the Study Design and Methods section.

\section{Current Status of the Project}

Since the inception of the video game metadata schema development by GAMER and SIMM in 2011, we have attempted to incorporate the strengths of all of the previously described evaluation methods where applicable. To ensure that we are reflecting as much domain expertise as possible, we conducted part of this research project in the form of a graduate-level course. It is almost impossible for any single person to have a comprehensive understanding of video games and interactive media across multiple platforms, genres, and time periods, so it was essential that we involve as many video game experts and enthusiasts as possible in the research process. In total, 21 people, including students, domain experts, and metadata professionals, participated in phase I of the project; 18 in phase II; and 15 in phase III. Table 1 outlines our previous and current research efforts for this project.

TABLE 1. Overview of the Previous and Current Research Efforts

\begin{tabular}{l|l|l}
\hline Timeline and Goals & Methods and Activities & Outcomes \\
\hline Phase I (2011-2012) & $\begin{array}{l}\text { Domain analysis: Examined how video } \\
\text { games are organized in current systems } \\
\text { Establish the core set } \\
\text { of elements for a } \\
\text { metadata schema } \\
\text { elements }\end{array}$ & $\begin{array}{l}\text { 16 CORE elements } \\
\text { identified and defined. }\end{array}$ \\
\cline { 2 - 3 } & $\begin{array}{l}\text { Personas: Evaluated the collected } \\
\text { metadata elements from domain analysis } \\
\text { based on six personas }\end{array}$ & \\
\hline Phase II (2012-2013) & $\begin{array}{l}\text { Domain analysis: Continued to explore } \\
\text { more game websites to collect additional } \\
\text { elements and terms that can be used for } \\
\text { 1) Establish the } \\
\text { recommended set of } \\
\text { elements for a } \\
\text { metadata schema }\end{array}$ & $\begin{array}{l}\text { 1) 46 REC (recommended) } \\
\text { elements (including } \\
\text { CORE16) identified and } \\
\text { defined based on user data } \\
\text { and facet analysis results. }\end{array}$ \\
\cline { 2 - 3 } & $\begin{array}{l}\text { User interview: Selected which metadata } \\
\text { elements are important to users based on } \\
\text { the in-depth interviews of 24 gamers }\end{array}$ & \\
\hline
\end{tabular}




\begin{tabular}{|c|c|c|}
\hline $\begin{array}{l}\text { 2) Develop encoding } \\
\text { schemes (controlled } \\
\text { vocabularies) for } \\
\text { select elements }\end{array}$ & $\begin{array}{l}\text { Facet analysis: Conducted a facet } \\
\text { analysis on select elements and defined } \\
\text { the facets and foci }\end{array}$ & $\begin{array}{l}\text { 2) New controlled } \\
\text { vocabularies created for } \\
17 \text { elements. }\end{array}$ \\
\hline \multirow{4}{*}{$\begin{array}{l}\text { Phase III (2013- } \\
\text { 2014) } \\
\text { Review and evaluation } \\
\text { of the current schema }\end{array}$} & $\begin{array}{l}\text { Collaborative review: Collaboratively } \\
\text { analyzed and revised the current } \\
\text { metadata schema and controlled } \\
\text { vocabularies }\end{array}$ & \multirow{4}{*}{$\begin{array}{l}\text { 1) CORE and REC } \\
\text { metadata sets thoroughly } \\
\text { revised based on the } \\
\text { additional user data and } \\
\text { feedback from metadata } \\
\text { record creators. } \\
\text { 2) Controlled vocabularies } \\
\text { for eight elements also } \\
\text { revised and new } \\
\text { controlled vocabularies } \\
\text { created for two additional } \\
\text { elements. }\end{array}$} \\
\hline & $\begin{array}{l}\text { Schema testing: Created metadata } \\
\text { records of } 65 \text { sample games in order to } \\
\text { test the applicability of the schema }\end{array}$ & \\
\hline & $\begin{array}{l}\text { User interview: Conducted } 32 \text { additional } \\
\text { interviews focusing on personas other } \\
\text { than gamers to gather feedback on the } \\
\text { schema }\end{array}$ & \\
\hline & $\begin{array}{l}\text { Survey: Conducted a large-scale survey } \\
\text { collecting } 1,257 \text { responses to obtain more } \\
\text { generalizable results }\end{array}$ & \\
\hline
\end{tabular}

In phase I, we conducted an extensive domain analysis using empirical data currently describing video games (Lee, Tennis, \& Clarke, (2012). We used existing information sources (i.e., a variety of video game-related websites and catalog records from sources such as Mobygames, Giantbomb, Allgame, Gamefaqs, Gamespot, IGN, Wikipedia, WorldCat, and Amazon) to understand how the domain has been shaped, how it is currently described, and where gaps appeared. We also developed six different personas-archetypes representing the needs, behaviors, and goals of a particular group of users (Cooper, 1999) - epitomizing the most common types of people interested in games. The six personas developed were representing game player, parent of youth game player, nostalgic collector, academic scholar, game developer/designer, and curator/librarian (Lee et al., 2013b). Based on these personas and several use scenarios, we evaluated the 61 elements and identified the 16 core elements deemed to be most useful for all user personas. These elements were further evaluated and revised based on cataloging sample games. More detailed information on our research activity in phase I can be found in Lee et al. (2013b).

In phase II, we established the recommended set of elements for a metadata schema (Lee, Cho, Fox, \& Perti, 2013a) and began developing encoding schemes/controlled vocabularies for select elements (Donovan, Cho, Magnifico, \& Lee, 2013; Lee, Karlova, Clarke, Thornton, \& Perti, 2014 b). In addition to the core 16, 30 additional elements were recommended to describe video games to the level of thoroughness useful to the various user groups. As we began to develop vocabularies for many of these elements, it became evident that metadata from extant sources significantly vary with regard to the types and granularity of the terms. For example, most websites did not provide definitions for genre labels, and those that did were not consistent with definitions from other sites. We also found that information sources varied widely in terms of reliability and availability. Dates and features varied, and descriptions of features were often colored by subjective marketing propaganda. Definitions and differences between "developer" and "publisher" were unclear. Differentiating among various editions of games was extremely challenging as a result of releases of the same game in multiple regions or for multiple consoles or systems, as well as special "collector's editions" or other limited special releases. Finding information on previous versions of digitally distributed games such as game apps for smartphones or tablets was also exceedingly difficult (Lee, Clarke, \& Perti, 2014a). 
In the current phase of the study, phase III, we focused on revising and evaluating the current schema and controlled vocabularies. There were two concurrent research streams: (a) refining the schema as a group and testing its applicability using sample games and (b) gathering user feedback on the schema through interviews and a large-scale online survey. More detailed discussion on research activities from phase III is provided in the following section.

\section{Study Design and Methods}

\section{Refining and Testing the Schema}

Collaborative review. The previous metadata work from phases I and II was revised through an iterative and collaborative expert review process. Each student independently wrote up his feedback on the initial list of personas, the elements and structure of the schema, and the controlled vocabularies, guided by personal expertise and experience with video games. To the method of expert review, we added a level of collaborative consensus, in which summary of the feedback was reviewed by the group, and every aspect was discussed until a convergence of views was achieved. As a result, new elements were included to make the schema more pertinent to digitally distributed games (Lee et al., 2014a). All definitions were refined, and instructions for identifying and extracting the metadata values were written for each element. Several controlled vocabularies were revised and two new vocabularies were created.

Schema testing. The schema and encoding schemes (syntax and vocabulary) were further evaluated by applying them to examples of video games to create sample metadata records of those games. These records were created by the students participating in the course. The students had a wide range of experience in cataloging (from novices to professionals) as well as gaming experience (from casual to dedicated gamers). As a group, they cataloged a total of 65 sample games which consisted of traditional console games for a variety of platforms, digitally distributed game apps, and flash-based games. The full list of sample games cataloged is provided in the Appendix (Table 6). Each game was cataloged twice according to the schema, once each by two different students. The results from comparing the two metadata records created for each game in conjunction with feedback from the students allowed us to identify successes, issues, and areas for improvement.

\section{User Evaluation of the Schema}

User interviews. In addition to the previous 24 interviews, we interviewed 32 participants, all over 18 years old, who find, play, purchase, collect, and recommend video games, to investigate their current practices. Unlike the case for phase II, in which the researchers focused mostly on interviewing gamers, in phase III the interviewees represented a wider range of user groups: three casual gamers, five avid gamers, four parents of youth players, six game collectors, five game industry professionals, six curators/librarians managing video game collections, and three scholars conducting game research. Interviewees were recruited by snowball sampling. Gamers were initially recruited via the SIMM's public exhibition and librarians via the American Library Association (ALA)'s annual conference and the Young Adult Library Services Association listserv. Scholars, employees, and parents were recruited via researchers' personal connections and references. Collectors were recruited via game-related forums. The interview protocol included specific questions about gaming experiences, game-related information needs and search behaviors, feedback on the current metadata schema, and so on. We were also interested in exploring what participants had to say about games. Interviews for some user groups had specific questions (e.g., librarians, people in game industry, parents, scholars). All the interviews were conducted between July and October 2013, in person, over the telephone, or on Skype. Each 
interview lasted for approximately 45 minutes to 1 hour. Each interviewee was compensated with a \$20 Amazon gift card for their participation.

Interviews were fully transcribed and analyzed to obtain a detailed qualitative description of behavior surrounding video game use, purchases, recommendations, organizational needs, and game seeking. The code book contained codes for various aspects, such as user behaviors, gamerelated resources, and appeal factors. The code book was created through an iterative coding process. Initially, we selected a subset of interview transcripts from which we developed a preliminary code book. Using this code book, two coders independently coded the transcripts once. A series of meetings discussing the code revisions followed. Using the revised code book that resulted from these meetings, the two coders reviewed and recoded the transcripts. Afterward, a third party reviewed all the coding work, identifying any issues and/or inconsistencies in applying the codes. The instances of questionable code applications were discussed among all three (i.e., two coders and the third-party reviewer) until consensus was reached. More detailed description of the coding process as well as a full discussion of findings is provided in another article in preparation (Lee, Clarke, \& Rossi, in preparation). The current article will focus primarily on user feedback with regard to the metadata.

Survey. We conducted a large-scale online survey asking 23 questions regarding users' gaming experience and game-related information needs and behaviors and five demographic questions. The objectives were to determine game-related information needs and behaviors that are commonly shared by a substantial number of users and to identify which information features are perceived as useful. Through this survey, we sought to validate our previous findings from interviews among a larger population.

The questionnaire consisted of five sections: (a) questions about gaming experience, (b) questions about physical games, (c) questions about digital games, (d) game-related information needs and search behaviors, and (e) demographics. The survey was administered via LimeSurvey, an online questionnaire tool, hosted on the University of Washington Information School's server.

Participants were limited to people over the age of 18 years who played video games. No specific game-playing behavior was necessary to participate in the survey (i.e., participants did not have to play a certain number of games or hours per week to participate). Participants were recruited through a variety of physical and online communication platforms, including various game-related mailing lists (e.g., ALA Connect - Games and gaming group, ATLUS forum); Facebook groups (e.g., International Game Developers Association, Extra Credits); UW iSchool student, faculty, and staff mailing lists; UW iSchool Research Fair; researchers' social networks; and so on. Many users on Facebook and other social media sites chose to share or forward links to their friends and various communities as well. The limitation on generalizing the findings of this survey to a larger population of gamers because of the sampling method should be noted. Participants were given the option of entering a raffle to win a total of $\$ 200$ worth of Amazon gift cards.

The survey was active for approximately 7 weeks from November 19, 2013, to December 30,2013 . In total, 2,163 respondents participated in the survey; of those, 1,257 completed the survey. Participants took an average of 20 minutes and 49 seconds to complete the survey.

\section{Findings and Discussion}

\section{Overview}

This section provides a summary of our findings from conducting a collaborative review, testing the schema, and analyzing the user feedback provided through an online survey and interviews. We describe each of the issues identified followed by an explanation of the changes made to the schema to address those issues. 
In the survey, we asked the users what information about games is most useful to them for games they are currently playing and also when they are looking for new games to play. Table 2 shows the complete list of metadata elements 4 sorted by the proportion of positive responses. The count in the sixth column represents the number of responses stating that the particular element is useful for at least one of the two cases (i.e., for games currently playing or in seeking new games).

TABLE 2. Metadata Elements Sorted by the Proportion of Positive Survey Responses to Their Usefulness

\begin{tabular}{|c|c|c|c|c|c|c|}
\hline & $\begin{array}{c}\text { Games } \\
\text { currently } \\
\text { playing }\end{array}$ & $\begin{array}{c}\text { Percent } \\
(\mathrm{N}=1257)\end{array}$ & $\begin{array}{c}\text { Seeking } \\
\text { new } \\
\text { games }\end{array}$ & $\begin{array}{c}\text { Percent } \\
(\mathrm{N}=1257)\end{array}$ & Count & $\begin{array}{c}\text { Percent } \\
(\mathrm{N}=1257)\end{array}$ \\
\hline Price & 245 & $19.5 \%$ & 998 & $79.4 \%$ & 1034 & $82.3 \%$ \\
\hline Platform & 594 & $47.3 \%$ & 956 & $76.1 \%$ & 1026 & $81.6 \%$ \\
\hline Genre & 589 & $46.9 \%$ & 930 & $74.0 \%$ & 996 & $79.2 \%$ \\
\hline Series & 533 & $42.4 \%$ & 881 & $70.1 \%$ & 953 & $75.8 \%$ \\
\hline Style & 528 & $42.0 \%$ & 864 & $68.7 \%$ & 922 & $73.3 \%$ \\
\hline Gameplay videos & 510 & $40.6 \%$ & 798 & $63.1 \%$ & 895 & $71.2 \%$ \\
\hline Plot/Narrative & 636 & $50.6 \%$ & 758 & $60.3 \%$ & 893 & $71.0 \%$ \\
\hline Franchise/Universe & 476 & $37.9 \%$ & 801 & $63.7 \%$ & 859 & $68.3 \%$ \\
\hline Theme & 505 & $40.2 \%$ & 776 & $61.7 \%$ & 843 & $67.1 \%$ \\
\hline Mood/Affect & 543 & $43.2 \%$ & 738 & $58.7 \%$ & 838 & $66.7 \%$ \\
\hline Title & 643 & $51.2 \%$ & 599 & $47.7 \%$ & 822 & $65.4 \%$ \\
\hline System requirements & 394 & $31.3 \%$ & 728 & $57.9 \%$ & 797 & $63.4 \%$ \\
\hline Developer & 307 & $24.4 \%$ & 730 & $58.1 \%$ & 774 & $61.6 \%$ \\
\hline Setting & 427 & $34.0 \%$ & 641 & $51.0 \%$ & 717 & $57.0 \%$ \\
\hline Format & 389 & $30.9 \%$ & 619 & $49.2 \%$ & 716 & $57.0 \%$ \\
\hline Trailers & 156 & $12.4 \%$ & 690 & $54.9 \%$ & 713 & $56.7 \%$ \\
\hline Number of players & 453 & $36.0 \%$ & 586 & $46.6 \%$ & 692 & $55.1 \%$ \\
\hline Distributor & 392 & $31.2 \%$ & 613 & $48.8 \%$ & 685 & $54.5 \%$ \\
\hline Retail Release Date & 114 & $9.1 \%$ & 656 & $52.2 \%$ & 684 & $54.4 \%$ \\
\hline Presentation & 396 & $31.5 \%$ & 610 & $48.5 \%$ & 674 & $53.6 \%$ \\
\hline Visual Style & 410 & $32.6 \%$ & 604 & $48.1 \%$ & 671 & $53.4 \%$ \\
\hline Online capabilities & 415 & $33.0 \%$ & 564 & $44.9 \%$ & 659 & $52.4 \%$ \\
\hline Point of View & 398 & $31.7 \%$ & 581 & $46.2 \%$ & 658 & $52.3 \%$ \\
\hline Customization options & 455 & $36.2 \%$ & 478 & $38.0 \%$ & 611 & $48.6 \%$ \\
\hline Screenshots & 167 & $13.3 \%$ & 566 & $45.0 \%$ & 593 & $47.2 \%$ \\
\hline Difficulty levels & 478 & $38.0 \%$ & 351 & $27.9 \%$ & 577 & $45.9 \%$ \\
\hline Type of ending & 432 & $34.4 \%$ & 388 & $30.9 \%$ & 572 & $45.5 \%$ \\
\hline Language & 320 & $25.5 \%$ & 498 & $39.6 \%$ & 559 & $44.5 \%$ \\
\hline Region & 241 & $19.2 \%$ & 500 & $39.8 \%$ & 545 & $43.4 \%$ \\
\hline Special hardware & 252 & $20.0 \%$ & 494 & $39.3 \%$ & 539 & $42.9 \%$ \\
\hline Temporal aspect & 319 & $25.4 \%$ & 461 & $36.7 \%$ & 527 & $41.9 \%$ \\
\hline Box art/Covers & 219 & $17.4 \%$ & 378 & $30.1 \%$ & 440 & $35.0 \%$ \\
\hline Packaging & 121 & $9.6 \%$ & 396 & $31.5 \%$ & 433 & $34.4 \%$ \\
\hline
\end{tabular}




\begin{tabular}{l|c|c|c|c|c|c}
\hline Edition & 179 & $14.2 \%$ & 331 & $26.3 \%$ & 421 & $33.5 \%$ \\
\hline Purpose & 215 & $17.1 \%$ & 365 & $28.3 \%$ & 415 & $33.0 \%$ \\
\hline $\begin{array}{l}\text { References to historical } \\
\text { events }\end{array}$ & 248 & $19.7 \%$ & 343 & $27.3 \%$ & 413 & $32.9 \%$ \\
\hline Official website & 277 & $22.0 \%$ & 337 & $26.8 \%$ & 411 & $32.7 \%$ \\
\hline Publisher & 143 & $11.4 \%$ & 368 & $29.3 \%$ & 410 & $32.6 \%$ \\
\hline $\begin{array}{l}\text { Achievements/Awards/ } \\
\text { Trophies }\end{array}$ & 341 & $27.1 \%$ & 160 & $12.7 \%$ & 384 & $30.5 \%$ \\
\hline Alternative title & 203 & $16.1 \%$ & 229 & $18.2 \%$ & 340 & $27.0 \%$ \\
\hline Game credits & 161 & $12.8 \%$ & 201 & $16.0 \%$ & 290 & $23.1 \%$ \\
\hline Rating & 108 & $8.6 \%$ & 235 & $18.7 \%$ & 279 & $22.2 \%$ \\
\hline Identifier & 60 & $4.8 \%$ & 92 & $7.3 \%$ & 135 & $10.7 \%$ \\
\hline
\end{tabular}

The elements < price $>$ and $<$ platform $>$ were the most highly rated, with over $80 \%$ of respondents stating they are useful. This was followed by a number of subject metadata elements (e.g., <genre $>$, <style >, <plot/narrative $>$, $<$ theme $>$, $<$ mood/affect $>$ ) and metadata about how the games are related to each other (e.g., $<$ series $>,<$ franchise/universe $>$ ). Visual information was also highly valued, most notably, <gameplay videos $>$. The usefulness of elements that are more closely tied to physical aspects of games (e.g., <identifier > [e.g., UPC], <packaging>, <box art/cover >) tended to be rated lower. It was also possible to confirm that the usefulness of certain elements does change depending on the information-seeking stage (i.e., already playing the game vs. seeking new games), as previous literature suggests (Google, 2012). The elements $<$ title $>,<$ difficulty level $>$, $<$ type of ending>, and <achievements/awards/trophies > were deemed more useful for the games that users are currently playing. All the other elements were deemed more useful for finding new games to play.

\section{Redefining the Personas}

Upon reviewing the interview transcripts from phase II, we determined that the original six personas were not fully representative of the variety of people who interact with video games. Therefore, several additional personas were added to better represent the types of individuals who might be interested in seeking information about video games. The newly added personas were representing the following user groups: educator/teacher, casual gamer (as opposed to avid gamer), and industry professional (specifically those who are not game designers/developers). A single person may have aspects of multiple user groups. This became evident as we interviewed more people. Despite our efforts to recruit people representing specific user groups, they often represented multiple user groups (e.g., casual gamer and parent; avid gamer and designer/developer).

\section{Patterns of Discrepancies among Catalogers}

Because of the nature of the highly descriptive data, we did not attempt to calculate specific quantitative measures for evaluating interindexer consistencies. Rather, we performed a qualitative review of consistencies of descriptions provided by different catalogers in order to identify problematic elements and patterns of discrepancies.

The most common discrepancies that emerged during cataloging regarded which conceptual level a cataloger was describing: work or manifestation? This was especially problematic for games available on multiple platforms (e.g., Candy Crush Saga for iTunes, Android, Facebook, etc.). Some chose to describe a game at the work level, listing all the platforms for which 
the game is available. Others chose to describe a game at the manifestation level, such as the specific instantiation on a particular platform. This resulted in discrepancies in the amount of information provided for some of the elements. This confusion about conceptual level of description inspired development of a conceptual model to inform catalogers about exactly which entity they are describing (e.g., game, game edition, local release, etc.; Jett, Sacchi, Lee, \& Clarke, in press).

Subjective elements such as $<$ plot $>$, $<$ theme $>$, and $<$ mood/affect $>$ require familiarity with the game or playing experience. Otherwise, the cataloger must rely on secondary sources (e.g., watching a gameplay video, reading a Wikipedia page) to determine such information. Because catalogers drew from different sources (i.e., personal experience of playing the game vs. research on the game), this sometimes resulted in inconsistent descriptions. To address this issue, we created a list of preferred sources of information for catalogers to reference.

Some catalogers reported that the large amount of information required to describe certain elements, such as <achievements/awards/trophies $>$, <customization options $>$, and <credits $>$, led to inconsistent recordings and might not result in a high return on investment of cataloger's time. We eliminated or modified these elements to narrow the scope, increase consistency, and reduce the workload.

Describing information for visual style of a game also led to discrepancy among catalogers because of a lack of understanding of and familiarity with terms for describing techniques used to create certain displays (e.g., rasterized, ray traced, low-poly). We decided to revise the controlled vocabulary to focus on the visual appearance rather than creation techniques. In addition, a followup user study is currently underway to test whether consistency can be improved with training materials. These materials contain a number of visual examples for each term, as requested by the catalogers.

\section{Relationships among Games}

Elements representing different relationships among related games (i.e., <series>, $<$ franchise/universe>) were deemed highly useful as evidenced by both the survey results and the interviews. This information seemed not only useful for gamers (e.g., "If I was looking for a new game to play, it would probably be like the series, because it [has] definite connection to something you know" [P27, avid gamer]), but also users who purchase games for other people (e.g., "My six year old likes... he loves Mario, just about any Mario game" [P48, parent]). Testing these elements by cataloging real games helped clarify that $<$ franchise $>$ and $<$ universe $>$ are not the same and therefore they should be split. The term < universe > is understood and used as a "super series," whereas $<$ franchise $>$ refers to the intellectual property associated with particular games and is related to marketing and commercial applications. The definition for the element $<$ franchise $>$ was revised to reflect this understanding, and <universe $>$ was removed, because this can be represented by using a recursive relationship for the element <series $>$. This discussion also led to the realization that development of a conceptual model will be necessary to represent the different relationships among games better. Furthermore, some interviewees were interested in searching and browsing games based on their influences on each other.

The other one is like the DNA of the game - this game influences this game. Those are things that even me right now I would be interested to see: that game influenced this game. That kind of circles back into "hey, these people like this game, then they also like this game." There's these connections that are sort of meta-connections between the games that are interesting to see from just a data point of view... It's like movies or song albums... (P38, industry professional). 
I think that's very important in games, because games, to a certain extent, a lot of games are pretty derivative of each other, and that's ok. You know, that's how things become refined and tracing the different paths of these strains of influence, go, tracing the directions they go is really great. (P20, avid gamer).

We expect that some of these influences may be inferred by elements such as <developer $>$, $<$ theme $>$, and <setting $>$; however, it would be potentially useful to include specifically some sort of "influenced by" relationship in the conceptual model to capture this information explicitly.

\section{Expansions/Alterations for Games}

Additional content for video games, such as downloadable content (DLC), modifications ("mods"), and patches, is an increasingly important aspect of gaming-distribution and revenue-generation models, particularly for digitally distributed games. The element <additional content $>$ was added to the schema to capture this information. In addition, increasing number of games are offering various ways for players to connect to other gamers and to online stores and servers. This being the case, information about <online capabilities> is highly relevant to many gamers (e.g., "Capability to connect online, for phone games especially, is really important. Cause I like knowing my rank in comparison to my friends" [P3, casual gamer]). To record more specific information related to $<$ online capabilities $>$, it was split into two separate elements, <networked features $>$ and $<$ connectivity $>$. The element $<$ networked features $>$ will be used to describe the ways in which the game can be experienced by connecting to other entities, such as online multiplayer, co-op mode, leaderboards, and content download, whereas <connectivity $>$ was created to capture the information about the technical requirements (e.g., hardware) necessary for connection. By "connection," we are referring not only to connecting to the Internet; many handheld game systems, such as Gameboy or GameGear, allow players to link their systems using a proprietary patch cable. The element <connectivity> is used to specify all these different types of connection that can be made among multiple systems. This is an increasingly important issue, especially for recent video game consoles (e.g., Xbox One initially attempting to require a user's periodic connection to the Internet to run the console) and is undoubtedly an important consideration for game players. There is also an unresolved issue of the instability of < networked features >-related information; a game's online server can be shut down because of diminishing popularity, or a company can decide to discontinue online services on a particular platform which will result in terminating online play features, leaderboards, and so on for many games ${ }^{5}$.

\section{Importance of Subject Metadata}

The usefulness of elements describing the content, subject, or the nature of users' experience of games such as <genre $>$, <style $>$, <plot/narrative $>$, $<$ theme $>$, and $<$ mood/affect $>$ was also highly rated by the survey participants. This is also resonated in a number of interviews:

So having that in there might help to, as a search term or as an organizational term, help to separate sub-genres of, you know, a plot/narrative or theme that, you know, this is a comical way to prevent the apocalypse versus a very serious way to prevent the apocalypse, which I think might be a kind of good way to organize (P28, gamer).

I think mood and affect are the ones probably the most important to me... because I play games for fun and entertainment and I don't want to be disturbed or scared or depressed by a video game (P2, casual gamer). 
Writing, and that's why I like the action-adventure, because there's usually a story to be told, it's not just "here's a gun, go kill that guy" kind of thing (P26, gamer).

Several interviewees also commented that, although the element <plot $>$ can be useful for grouping games with similar plots together, they need additional information on what the game is really about. Some concern was raised with regard to what level of granularity should be used to describe the plot:

I think if you go too detailed then you are kind of giving away parts of the game, but if you go too general, I would say that these examples would be slightly too general for me to be particularly interested in the game. Particularly because lots of games are where the protagonist explores the world. That's Mario, that's most MMOs are kind of, you're just basically exploring the world and finding quests (P28, gamer).

The new element < summary> was added to address this issue and provide more detailed information about a game's narratives. This information would not be used for collocation purposes but rather to help users make informed decisions about individual games. <Theme> was also mentioned as useful because it can aid users' decisions on playing a particular game (e.g., "I guess also theme would be a big one, because one of the options here is supernatural zombies, I'm not going to play a game with zombies... it is too real in the game" [P2, casual gamer]; "I work with a community called Queer Geek which is a GLBTQ, anything that has like a minority presences [sic] in game [would be useful]" [P11, avid gamer]).

In addition, the element <links to historical events $>$ is now subsumed under <setting $>$ to remove duplication of data. $<$ Setting $>$ was revised to have three facets: spatial, temporal, and cultural. Under each facet, the value will be qualified as "real" or "imagined." < Setting > can provide more information about the gameplay in addition to <genre> (e.g., "This is the kinda, it's set in modern times in the city, you know, kinda giving them a sense of what the gameplay is like" [P43, curator/librarian]). Information about the connection to historical events may be useful for gamers as well as parents and educators (e.g., "[T]hey each have historical things that they're crazy about. Like I said, [name redacted] is very WWII, but [name redacted] is very interested in Roman history and the American Revolution, which is why Assassin's Creed is so interesting to him, so yeah, they definitely would care very much about that" [P47, parent]). The element <temporal aspect $>$ was also renamed to the more commonly used term < pacing > based on user warrant. An issue was raised during the review process that there can be multiple dimensions of time flow in a game. As a result, three different temporal aspects will be represented in this element: "battle system" (i.e., how the time flows in a battle), "in-game clock" (i.e., how the time passes in the game world), and "time manipulation" (i.e., how characters interact with time). For instance, Final Fantasy: Lightning Returns has a real-time battle system, the in-game clock runs continuously during the gameplay, and the protagonist is able to stop the time temporarily. As some interviewees suggested, this information can be critical for gameplay (e.g., "When you say a turn-based strategy game, rather than RTS [real-time strategy], those are different genres...They play differently because time is used differently" [P53, scholar]).

\section{Need for Visual Metadata}

Among the four different kinds of visual information about games (i.e., <gameplay videos>, $<$ trailers $>$, <screenshots $>$, < box art/cover $>$ ), survey respondents found < gameplay videos $>$ to be most useful, and this was often mentioned as highly useful by interviewees as well: 
Even though it looks cute from a still image or if I want to see also [if] it is too simple, you can only get that from seeing someone actually play and that would also get at possibly how difficult controls are and how difficult it is to actually play the game a little bit (P2, casual gamer).

I flat out don't like playing sports games, racing games, and fighting games as much, but that you can sort of figure out with the gameplay videos. Even if it's a genre you don't really like, I don't really like fighting games, but I like Super Smash Bros. I can discern that from the gameplay video (P37, industry professional).

Definitely the gameplay video, that is going to sway me one way or the other. If something is like a polished piece and it looks well and it is well presented and it looks like something I've played before or something I would like to play, then that's probably [going to] get me to spend my money (P22, gamer).

Interviewees seem to think that trailers would be more entertaining than informing (e.g., "[T]railers are entertaining but it is usually just the CG [computer graphics] animated thing that is not even related to the game and it's not actual gameplay" [P22, avid gamer]). Screenshots may be problematic because it can be difficult to determine whether they are from pregenerated video clips, actual gameplay, or fan-created artwork (e.g., "I feel like the problem with screenshots at least in my mind is veracity; how do you determine that a screenshot is actually from the game that you're claiming it's from?" [P5, collector]).

\section{Challenging Descriptive Metadata}

Several descriptive metadata elements were particularly difficult to deal with because of such issues as the lack of available information sources, instability of information, and so on. $<$ Price $>$, for instance, was identified by our survey participants as the most useful element but was particularly difficult for our catalogers to research and transcribe in a straightforward manner. Reasons for the difficulty included (a) lack of immediately available primary sources from which to derive the information, (b) regular price fluctuations of both physically and digitally distributed games, and (c) lack of supporting metadata to give context to the price. To address these issues at least partially, the date when the price information was captured and the source of the information will be recorded as qualifiers with this metadata element.

In addition, the <region> element had to be revised from its previously broad definition of "the names used to refer to a place, region, or territory where a game is designated as playable." This definition turned out to be problematic because it was not always clear how one determines whether a game is playable in certain regions. For instance, if a game app is released in certain languages, does that mean the game was intended to be playable only in the regions where those languages are spoken? The element was renamed and redefined so that it better reflects the overall intent, which was to provide users with necessary information to play a particular game release (e.g., knowing whether they will be able to play the game they bought in Japan on their PlayStation).

Region would be very important... My kids are always like, oh it's out in Japan but not here. It's here but my friend in Portugal doesn't have it. Especially for things that have online components, they want to play with their friends that they've made all over the globe. Or people that they've met in fandoms (P39, curator/librarian).

Such information is multitiered, requiring in-depth knowledge of electronic circuitry, digital rights management (DRM), analog/digital signal processing, and more prevalently, approximate 
physical location. Game companies sum up these needs into their own proprietary region codes, which often differ from system to system. The new definition specifically refers to "the classification code indicating the video encoding and regional hardware necessary to realize the game" (e.g., North America NTSC-U/C; Japan and Asia NTSC-J). An issue remains that many older games, as it turns out, do not have region codes printed on the box, manual, or cartridge, often leading to confusion as to what exactly is required to play the game in terms of both hardware and software. A comprehensive analysis of the technical specifics as well as the way in which companies describe region in their own games must be performed to create a useful controlled vocabulary.

\section{Issues in Describing Digitally Distributed Games}

The elements < format $>$, <packaging $>$, and < box art/cover $>$ turned out to be problematic, particularly for describing digitally distributed games. By "digitally distributed games," we are referring to games that have no physical container or component, and are accessible only through download or streaming (Lee et al., 2014b). The term "born-digital" in the controlled vocabulary for $<$ format $>$ was revised because of the lack of specificity in describing different varieties of digitally distributed games, such as downloadable, flash-based, and streaming games. Additionally, it is the nature of video games that they are all born-digital from a developmental and carrier standpoint, so it was an inappropriate term for describing games that have no physical component. The name of the element < box art/cover > was changed to < representative art > to ensure its applicability to digitally distributed games in addition to physical games. The definition of <packaging $>$ was revised so that it clearly states its applicability to physical games alone.

In addition, there were 16 survey responses to the open-ended question asking for other useful information that specifically mentioned DRM. Five of these responses simply referred to DRM without further specification. Two mentioned desires for DRM-free games. The remainder commented on specific DRM restrictions, such as "a limited amount of installs per license or games that demand that you log into a server to play a single player game is horrible," "allways [sic] online is a nightmare," and "does it require that the CD be in the drive at all times?" Some respondents specifically mentioned wanting to avoid "intrusive DRM" and wanted to know what types of DRM and other limitations apply to a particular game before they purchase it. This information not only is useful to game players from a practical viewpoint but also can be of interest to game scholars studying the legal aspects of gaming. The researchers decided to include this new metadata element with an expectation that this will be increasingly important as digitally distributed games become more prevalent (e.g., "The game starts out with DRM, and then they take it away; [it] changes the game in sort of a very fundamental way, particularly if the game is online or needs to be online to function. So I feel like digital rights management, even if it's just a yes or no tick box could be important, and necessarily important for the platform that it's on" [P5, collector]). Information regarding limited install activation; persistent online authentication; software tampering; and rights to copy, share, and resell the game will be recorded under this element. We expect in our future work to develop this controlled vocabulary further to fully represent the wide variety of DRM techniques and technologies.

\section{Managing Complexity}

Some elements were removed from the recommended set and some elements were simplified to avoid putting undue burden on catalogers, as will be explained.

Characters. For many catalogers, this element quickly became an unruly mess and unavoidable time expense. Complications were numerous, some of which cannot be easily solved. First, it is difficult to clearly indicate what constitutes a main character. Criteria such as being a playable character or named character were immediately met with counterexamples (e.g., main antagonist 
in the game who is not playable, unnamed [customizable] protagonist). Also, particular characters can appear across multiple games in a series, but it can be unclear whether they are in fact the same character (e.g., all the Links in the Legend of Zelda series). Other issues include the ambiguity regarding types and depth of information to be transcribed, the sheer number of characters in some cases, the lack of a controlled vocabulary to handle the ascription, how to handle non-playable characters, and how to gauge the necessity of ascribing one character over another in a game. Considering the level of complexity that this element brings to the schema, it was decided that a separate database of game characters specifying the source of and relationships among the characters would have to be established to describe this information in a satisfying manner.

Controls. This element was challenged for the following reasons: (a) for certain titles, the list of controls can be quite extensive and can vary from character to character (e.g., a role-playing game (RPG) title with multiple playable characters who have their own set of attack, magic and healing spells), making it difficult to discern which controls should be included, and (b) for certain titles, the controls can actually be reprogrammed by the player. The potential usefulness of describing this information in a metadata record was also unclear, because most newer games, especially digitally distributed games, come with tutorials embedded in the games themselves. This led to the decision to remove <controls> from the recommended set of elements and place it in a more comprehensive full set, currently under development.

Achievements, awards, trophies. There were two main issues with this element: (a) this is a very detailed level of information that may contain spoilers, and (b) it was unclear to the catalogers what exactly constitutes an achievement. The original intent was to record only the preprogrammed ingame achievements based on specific consoles (e.g., PlayStation Trophies, Xbox Achievements). However, this was challenged by multiple games on Steam that have growing numbers of achievements as new patches are released (e.g., Team Fortress 2 was launched with 17 achievements that later grew to 477 achievements ${ }^{6}$ ). The researchers determined that this information is better represented and managed in a game wiki rather than in the metadata record and so decided to remove this element.

Credits. This element was removed from the recommended set for the following reasons: credits turned out to be exceptionally inconsistent from one game to the next, and after examining the credits information from multiple games, it became clear that a wide variety of job titles are used without clear indications of how the people actually contributed to creating the game. There is also the issue of authority control; we need to be able to attribute the work to the right person. For that, we need an authority file of people involved in the video game industry. Further research is necessary for $<$ credits $>$ to be included as a viable element in the schema.

Visual style. The visual style was deemed useful by over $50 \%$ of the survey participants and also was mentioned several times by multiple interviewees as important. However, several catalogers mentioned that it was difficult to determine the visual style of sample games, in particular, the technique facet. The technique facet was designed to represent information on the tools and techniques used to render the visuals. This may be highly relevant to game developers/designers but has less significance to average game players. The interview data suggested that what mattered more to users was the visual style and dimension information that reflected how they experienced the game, rather than the techniques and technologies used to create that experience. (e.g., "The visual style, I usually play realistic game or cel-shaded graphics, that's what I play too; that's the comic book style" [P22, avid gamer]). Therefore we decided to keep <visual style > and <dimension> as two separate elements in the recommended metadata set and leave the visual technique to be included in the larger full set. 
Customization options. Testing the schema revealed that the criteria for inclusion in this element required further specification. Numerous things can be customized in many games, such as characters, difficulty levels, display, and sound. This quickly became excessively complicated. After much discussion, the researchers decided to describe only two particular customization options under this element: characters (e.g., "I'm thinking about the Mass Effect games, they'll come in and say that they loved how customizable it is" [P39, curator/librarian]; "I really did like that in Mass Effect you can make your own person which is pretty cool. I made it [to] look like me" [P22, avid gamer]) and difficulty levels (e.g., "Difficulty levels are important, I like to feel challenged, and I like to be able to advance and have a sense of completion." [P22, avid gamer]), because these were most commonly mentioned by the interviewees.

\section{Revised Version of the Schema}

The schema was further refined to version 2.0 based on the collaborative review, creating metadata records of 65 sample games, feedback from the student catalogers, and user data from the interviews and the survey. Table 3 presents the elements, definitions, and instructions from version 2.0. We also provide a crosswalk table (Table 4) comparing our schema with other general schemas/standards that are typically used in cultural-heritage institutions: in particular, Dublin Core, machine-readable cataloging (MARC), and Resource Description and Access (RDA). The lack of comparable elements in other schemas/standards illustrates the limitations of using them to describe video games fully.

TABLE 3. Metadata Elements from the Revised Schema

\begin{tabular}{l|l}
\hline Element & Definition and Instruction \\
\hline Title & $\begin{array}{l}\text { Proper names that are used to refer to a video game, assigned by the creator. } \\
\text { (modified from CIDOC CRM, 2014, p.16) }\end{array}$ \\
\hline Edition & $\begin{array}{l}\text { A word or phrase appearing in the game being described that indicates a } \\
\text { difference in either content or form between it and a related game (e.g., second } \\
\text { edition, greatest hits, collector's edition, limited edition). (modified from FRBR, } \\
\text { 2009, p. 41) }\end{array}$ \\
\hline Feries & $\begin{array}{l}\text { Proper names of a set of related games, often indicated by consecutive } \\
\text { numbering, continuing narrative, or similarities in gameplay and themes, to } \\
\text { which the game being described belongs. }\end{array}$ \\
\hline Corporate body & $\begin{array}{l}\text { A commonly used name referring to the intellectual property, related data, and } \\
\text { content shared among a group of cultural objects to which the game being } \\
\text { described belongs. }\end{array}$ \\
\hline Platform & $\begin{array}{l}\text { for creation, realization, manufacture, marketing, and/or distribution of a game. } \\
\text { (modified from FRBR, 2009, p.25) }\end{array}$ \\
\hline Format & $\begin{array}{l}\text { The hardware and operating system on which the game was designed to be } \\
\text { played. (e.g. PlayStation 3; Xbox 360; Nintendo 3DS; Android 4.4 KitKat; Apple } \\
\text { iOS 7, PC Windows XP, Mac OS X) }\end{array}$ \\
\hline $\begin{array}{l}\text { The distribution medium or method that provides the executable code of a video } \\
\text { game. (e.g. cartridge, optical, magnetic, downloadable, streaming) }\end{array}$ \\
\hline
\end{tabular}




\begin{tabular}{|c|c|}
\hline $\begin{array}{l}\text { System } \\
\text { requirements }\end{array}$ & $\begin{array}{l}\text { Hardware, firmware, and/or software components that are prerequisites for } \\
\text { running the game on a particular platform. (e.g. 2GB RAM, 8GB Hard Disk Space, } \\
\text { DirectX 9.0C, 256MB ATI HD26000 XT Video Card, DirectX 9.0c Compatible } \\
\text { Sound Card, Quad Core 1.8GHz Processor) }\end{array}$ \\
\hline $\begin{array}{l}\text { Special } \\
\text { hardware }\end{array}$ & $\begin{array}{l}\text { A hardware that is required or recommended for playing the game in addition to } \\
\text { the main platform. (e.g. motion controller; gaming headset) }\end{array}$ \\
\hline $\begin{array}{l}\text { Networked } \\
\text { features }\end{array}$ & $\begin{array}{l}\text { The ways in which the game can be experienced through connection(s) to other } \\
\text { entities, such as game companies, third-party organizations, and other players. } \\
\text { (e.g., online multiplayer, content download, leaderboards, voice, spectators) }\end{array}$ \\
\hline Connectivity & $\begin{array}{l}\text { The technology through which the networked features are realized. (e.g., Client- } \\
\text { server based, Ad-hoc, Broadband, LAN) }\end{array}$ \\
\hline DRM & Digital rights management technologies intended to control the use of the game. \\
\hline $\begin{array}{l}\text { Additional } \\
\text { content }\end{array}$ & $\begin{array}{l}\text { The type and the name of the additional content including DLC, mod, patches, } \\
\text { and so on. }\end{array}$ \\
\hline $\begin{array}{l}\text { Number of } \\
\text { players }\end{array}$ & $\begin{array}{l}\text { The number or range of the number of players the game can accommodate either } \\
\text { separately or concurrently. }\end{array}$ \\
\hline Region code & $\begin{array}{l}\text { The classification code that indicates the video encoding and regional hardware } \\
\text { necessary to realize the game. (e.g., North America NTSC-U/C; Japan and Asia } \\
\text { NTSC-J; Europe, New Zealand and Australia PAL; China NTSC-C) }\end{array}$ \\
\hline Language & $\begin{array}{l}\text { The classification code for the language(s) in which the game conveys } \\
\text { information. }\end{array}$ \\
\hline $\begin{array}{l}\text { Retail release } \\
\text { date }\end{array}$ & The date of the public/commercial release of the game. \\
\hline Rating & $\begin{array}{l}\text { The classification of the content in the video game for informed decision making } \\
\text { about the game, provided by organizations such as professional associations, } \\
\text { game distributors, or creators. (e.g., MA-13 Parental Discretion Advised. Mature } \\
\text { Audiences; Everyone. E. (ESRB)). Note that some older games do not have this } \\
\text { rating information. }\end{array}$ \\
\hline Official website & $\begin{array}{l}\text { A URL of the website for the game from the companies officially associated with } \\
\text { the game. }\end{array}$ \\
\hline Price/MSRP & $\begin{array}{l}\text { The manufacturer's suggested retail price (MSRP) at time of initial release in the } \\
\text { country or region where the game was released. }\end{array}$ \\
\hline Award & $\begin{array}{l}\text { The names(s) of any awards the game has won and the granting body that } \\
\text { awarded them. }\end{array}$ \\
\hline $\begin{array}{l}\text { Customization } \\
\text { options }\end{array}$ & $\begin{array}{l}\text { The in-game options for difficulty level and characters which can be modified by } \\
\text { the player for personalized experience. }\end{array}$ \\
\hline Packaging & $\begin{array}{l}\text { All items included in the original packaging of the game. (e.g. } 2 \text { game discs, } \\
\text { soundtrack, manual, action figures) }\end{array}$ \\
\hline Genre & $\begin{array}{l}\text { The overall nature of a game based on its objectives, types of rules, distinctive } \\
\text { characteristics, modes of action, manners of gameplay, and how a player } \\
\text { interacts with it. }\end{array}$ \\
\hline Plot & The underlying events that make up the story of the game. \\
\hline Summary & A brief statement or account of the main points of the game. \\
\hline Theme & $\begin{array}{l}\text { A common thread, motif, subject, or idea that recurs in the game. (modified from } \\
\text { Getty Art \& Architecture Thesaurus) (e.g. fantasy-princess; supernatural- } \\
\text { zombies) }\end{array}$ \\
\hline Setting & The location, time frame, and/or cultural context in which the game takes place. \\
\hline
\end{tabular}




\begin{tabular}{l|l}
\hline Mood & $\begin{array}{l}\text { The pervading atmosphere or tone of the video game which evokes or recalls a } \\
\text { certain emotion or state of mind. }\end{array}$ \\
\hline Pacing & $\begin{array}{l}\text { The methods by which time passes in the game and/or manner in which events } \\
\text { take place. }\end{array}$ \\
\hline $\begin{array}{l}\text { Estimated time } \\
\text { of completion }\end{array}$ & The estimated average time to complete the game. \\
\hline Type of ending & The characteristics describing how the game ends and/or post-game content. \\
\hline Visual style & $\begin{array}{l}\text { The predominant and recognizable visual appearance of a video game as } \\
\text { originally intended by its creator, and/or determined in the context of creation. }\end{array}$ \\
\hline Dimension & $\begin{array}{l}\text { The intended perception of the depth of the represented entities inside the game. } \\
\text { (e.g., 2D, 3D, Stereoscopic 3D, Multiple) }\end{array}$ \\
\hline Point of view & $\begin{array}{l}\text { Perspective from which the player experiences the gameplay. (e.g. first person; } \\
\text { third person) }\end{array}$ \\
\hline $\begin{array}{l}\text { Representative } \\
\text { art }\end{array}$ & $\begin{array}{l}\text { The officially released image that is representative of the game, prominently } \\
\text { featured in a physical or digital distribution package }\end{array}$ \\
\hline Screenshots & Still images taken during the gameplay. \\
\hline Trailers & $\begin{array}{l}\text { Video footage released and/or endorsed by the developer/publisher of the game } \\
\text { for promotional purposes. }\end{array}$ \\
\hline $\begin{array}{l}\text { Game-play } \\
\text { videos }\end{array}$ & $\begin{array}{l}\text { Video footage of the game-play excluding such things as introductions, cutscenes, } \\
\text { or trailers. }\end{array}$ \\
\hline Note & Any other notable characteristics of the game. \\
\hline
\end{tabular}

TABLE 4. Metadata Crosswalk Table ${ }^{7}$

\begin{tabular}{|c|c|c|c|}
\hline Our schema & DC Terms & MARC fields & RDA no. \\
\hline Title $[\mathrm{M}][\mathrm{R}]$ & title & $245 a$ & 5.1 .3 \\
\hline Edition & $\begin{array}{l}\text { hasVersion; } \\
\text { isVersionOf }\end{array}$ & 250 & 2.5 .1 \\
\hline Series [R] & isPartOf & 490 & 2.12 \\
\hline \multicolumn{4}{|l|}{ Franchise [R] } \\
\hline Corporate body $[\mathrm{M}][\mathrm{R}]$ & creator; publisher & 110 & 11.2 \\
\hline Platform [M][R] & & 337 & 3.2 \\
\hline Format $[\mathrm{M}]$ & format & 338 & 3.3 \\
\hline $\begin{array}{l}\text { System requirements } \\
\text { [R] }\end{array}$ & requires & 538 & 3.20 \\
\hline Special hardware [R] & requires & 538 & 3.20 \\
\hline \multicolumn{4}{|l|}{$\begin{array}{l}\text { Networked features } \\
{[\mathrm{R}]}\end{array}$} \\
\hline \multicolumn{4}{|l|}{ Connectivity [R] } \\
\hline DRM [R] & $\begin{array}{l}\text { license } \\
\text { accessRights }\end{array}$ & $506 ; 540$ & $\begin{array}{l}4.4 \\
4.5\end{array}$ \\
\hline Additional content [R] & isReferencedBy & 525 & $\begin{array}{l}\text { J3.5; J4.5; J5.5 (varies } \\
\text { depending on FRBR } \\
\text { level) }\end{array}$ \\
\hline \multicolumn{4}{|l|}{$\begin{array}{l}\text { Number of players } \\
{[\mathrm{M}][\mathrm{R}]}\end{array}$} \\
\hline Region code $[\mathrm{M}][\mathrm{R}]$ & & 044 & 3.19 .6 \\
\hline
\end{tabular}




\begin{tabular}{|c|c|c|c|}
\hline Language $[\mathrm{R}]$ & language & 041 & 6.11 \\
\hline $\begin{array}{l}\text { Retail release date } \\
{[\mathrm{M}][\mathrm{R}]}\end{array}$ & issued & $260 \$ c$ & 2.8 \\
\hline Rating [R] & audience & 521 & 7.7 \\
\hline Official website $[\mathrm{R}]$ & relation & $856 u$ & 4.6 \\
\hline Price/MSRP [R] & & 365 & 4.2 .1 .3 \\
\hline Award [R] & & 586 & 7.28 \\
\hline \multicolumn{4}{|l|}{ Customization options } \\
\hline Packaging & & 300 & 3.4 \\
\hline Genre $[\mathrm{M}][\mathrm{R}]$ & type & 655 & 6.3 \\
\hline Plot $[\mathrm{R}]$ & abstract & 520 & 7.10 \\
\hline Summary & abstract & 520 & 7.10 \\
\hline Theme [R] & subject & 650 & 13 \\
\hline Setting $[\mathrm{R}]$ & coverage & 651 & \\
\hline \multicolumn{4}{|l|}{$\operatorname{Mood}[\mathrm{R}]$} \\
\hline \multicolumn{4}{|l|}{ Pacing } \\
\hline $\begin{array}{l}\text { Estimated time of } \\
\text { completion }\end{array}$ & & & 7.22 \\
\hline \multicolumn{4}{|l|}{ Type of ending } \\
\hline Visual style $[\mathrm{R}]$ & & 650 & \\
\hline Dimension & & & $\begin{array}{l}3.17 .2 \text { (for motion } \\
\text { picture film) }\end{array}$ \\
\hline \multicolumn{4}{|l|}{ Point of view } \\
\hline Representative art [R] & description & & \\
\hline Screenshots [R] & $\begin{array}{l}\text { hasPart } \\
\text { relation }\end{array}$ & & $\mathrm{J} 3.5$ \\
\hline Trailers [R] & relation & & J3.5 \\
\hline Game-play videos [R] & $\begin{array}{l}\text { hasPart } \\
\text { relation }\end{array}$ & & J3.5 \\
\hline Note & & 500 & 5.9 \\
\hline
\end{tabular}

\section{Conclusion and Future Work}

Video games are an important part of our cultural heritage. Games foster human expressiveness and reflect how we define ourselves in current history (Monnens et al., 2009). It is of utmost importance to organize, describe, and preserve this legacy for future generations. Our work from the past 3 years is only a start in pursuing this immense and critical research agenda.

This is an ongoing research effort; we continue to work on refining the elements and definitions to represent new types of games better. We also plan to continue to work on creating controlled vocabularies for the new metadata elements such as $<$ connectivity $>$, <networked features $>$, and <additional content $>$, and revising the vocabularies for elements such as <format $>$ and $<$ theme $>$. In addition, there is a separate research stream to develop a metadata application profile based on CIDOC CRM (ICOM/CIDOC Documentation Standards Group, 2014), specifically targeted for game museums. This metadata profile will include a number of additional administrative elements as well as item-level descriptions (e.g., provenance, value, display record).

Even with a comprehensive list of metadata elements, there is still information that is not easy to represent. The complex relationships that exist among games (e.g., series, influences) are particularly tricky. To represent these relationships fully, the authors have been developing a conceptual model (Jett et al., in press). The revised metadata elements discussed in this article will 
be fully incorporated into the model. We expect that the conceptual model can be extended to represent ephemera and other materials related to games, such as action figures, artwork, and music, to create a robust and holistic representation of the video game domain that serves users' needs.

\section{Acknowledgements}

We would like to thank everyone who participated in the interviews and survey and helped recruit participants by sharing our invitations. We extend special thanks to the students in the INF0498/INFX598 video game metadata courses for their valuable contributions in revising the interview and survey questions, and James Portnow at DigiPen for his help in recruiting survey participants. This research is supported by the Bridge Award from the Office of Research at the University of Washington.

\section{References}

Beak, J., \& Olson, H.A. (2011). Analysis of metadata schemas for children's libraries. In R.P. Smiraglia (Ed.), Proceedings from North American Symposium on Knowledge Organization (Vol. 3 pp. 1-12). Toronto, Canada: International Society for Knowledge Organization.

Bloomfield, M. (2001). Indexing: Neglected and poorly understood. Cataloging \& Classification Quarterly, 33(1), 63-75.

Bruce, T.R., \& Hillmann, D.I. (2004). The continuum of metadata quality: Defining, expressing, exploiting. In D. Hillmann \& E. Westbrooks (Eds.), Metadata in practice (pp. 238-256). Chicago: American Library Association. Retrieved from http://ecommons.library.cornell.edu/handle/1813/7895

Cooper, A. (1999). The inmates are running the asylum. Indianapolis: Sams.

Crookes, D. (2012). British Library starts videogame website archive project. Retrieved from http://www.independent.co.uk/life-style/gadgets-and-tech/news/british-library-startsvideogame-websitearchive-project-6858507.html

Currier, S., Barton, J., O’Beirne, R., \& Ryan, B. (2004). Quality assurance for digital learning object repositories: Issues for the metadata creation process. ALT-J Research in Learning Technology, 12(1), 5-20.

Donovan, A., Cho, H., Magnifico, C., \& Lee, J.H. (2013). Pretty as a pixel: Issues and challenges in developing a controlled vocabulary for video game visual styles. In Proceedings of the 13th ACM/IEEE-CS Joint Conference on Digital Libraries (pp. 413-414). New York: ACM.

Funk, M.E., Reid, C.A., \& McGoogan, L.S. (1983). Indexing consistency in Medline. Bulletin of the Medical Library Association, 71(2), 176-183.

Google. (2012). Understanding the modern gamer. Retrieved from http://www.thinkwithgoogle.com/research-studies/understanding-the-modern-gamer.html

Greenberg, J., Pattuelli, M.C., Parsia, B., \& Robertson, W. D. (2001). Author-generated Dublin Core metadata for web resources: A baseline study in an organization. In Proceedings of the 
International Conference on Dublin Core and Metadata Applications (pp. 38-46). Retrieved from http://www.nii.ac.jp/dc2001/proceedings/product/paper-06.pdf

Guy, M., Powell, A., \& Day, M. (2004). Improving the quality of metadata in e-print archives. Ariadne, 38. Retrieved from http://www.ariadne.ac.uk/issue38/guy/

Hillmann, D.I. (2008). Metadata quality: From evaluation to augmentation. Cataloging \& Classification Quarterly, 46(1), 65-80.

Hughes, A.V. \& Rafferty, P. (2011). Inter-indexer consistency in graphic materials indexing at the National Library of Wales. Journal of Documentation, 67(1), 9-32.

ICOM/CIDOC Documentation Standards Group (2014). Definition of the CIDOC Conceptual Reference Model. Retrieved from http://www.cidoc-crm.org/docs/cidoc_crm_version_5.1.2.pdf

IFLA Study Group on the FRBR, IFLA Section on Cataloging, Standing Committee. (2009). Functional requirements for bibliographic records: Final report. München, Germany: Saur Verlag.

Jett, J., Sacchi, S., Lee, J.H., \& Clarke, R.I. (in press). A conceptual model for video games and interactive media. Submitted to Journal of the Association for Information Science and Technology.

Lee, J.H., Tennis, J.T., \& Clarke, R.I. (2012). Domain analysis for a video game metadata schema: Issues and challenges. Theory and Practice of Digital Libraries, Lecture Notes in Computer Science, $7489,280-285$.

Lee, J.H., Cho, H., Fox, V., \& Perti, A. (2013a). User-centered approach in creating a metadata schema for video games and interactive media. In Proceedings of the 13th ACM/IEEE-CS Joint Conference on Digital Libraries (pp. 229-238). New York: ACM.

Lee, J.H., Tennis, J.T., Clarke, R.I., \& Carpenter, M. (2013b). Developing a video game metadata schema for the Seattle Interactive Media Museum. International Journal on Digital Libraries, 13(2), 105-117.

Lee, J.H., Clarke, R.I., \& Perti, A. (2014a). Metadata for digitally distributed video games at the Seattle Interactive Media Museum. In N. Proctor \& R. Cherry (Eds.), Museums and the Web 2014. Silver Spring, MD: Museums and the Web. Retrieved from http://mw2014.museumsandtheweb.com/paper/metadata-for-digital-video-games-at-the-seattleinteractive-media-museum/

Lee, J.H., Karlova, N.A., Clarke, R.I., Thornton, K., \& Perti, A. (2014b). Facet analysis of video game genres. In Proceedings of the iConference 2014 (pp. 125-139). iSchools.

Lee, J.H., Clarke, R.I., \& Rossi, S. (in preparation). A qualitative investigation of users' video game information needs and behaviors.

McDonough, J., Olendorf, R., Kirschenbaum, M., Kraus, K., Reisde, D., Donahue, R., \& Rojo, S. (2010). Preserving virtual worlds final report. Retrieved from http://hdl.handle.net/2142/17097 
Moen, W.E., Steward, E.L. \&. McClure, C.R. (1997). The role of content analysis in evaluating metadata for the U.S. Government Information Locator Service: Results from an exploratory study. Retrieved from http://www.unt.edu/wmoen/publications/GILSMDContentAnalysis.htm

Monnens, D., Armstrong, A., Ruggill, J., McAllister, K., Vowell, Z., \& Donahue, R. (2009). Before it's too late: A digital game preservation white paper. Retrieved from http://wiki.igda.org/images/a/ab/IGDA_Game_Preservation_SIG_-_Before_It's_Too_Late__A_Digital_Game_Preservation_White_Paper.odt

National Information Standards Organization (NISO). (2007). A framework of guidance for building good digital collections. Bethesda, MD: NISO Press. Retrieved from

http://www.niso.org/publications/rp/framework3.pdf

Newman, J. (2009). Save the videogame! The national videogame archive: Preservation, supersession and obsolescene. M/C Journal, 12(3). Retrieved from http://journal.mediaculture.org.au/index.php/mcjournal/article/viewArticle/167

Owens, T. (2012). Yes, the Library of Congress has video games: An interview with David Gibson. Retrieved from http://blogs.loc.gov/digitalpreservation/2012/09/yes-the-library-of-congress-hasvideo-games-aninterview-with-david-gibson/

Park, J. (2009). Metadata quality in digital repositories: A survey of the current state of the art. Cataloging \& Classification Quarterly, 47(3/4), 213-228.

Shukair, G., Loutas, N., Peristeras, V., \& Sklarß, S. (2013). Towards semantically interoperable metadata repositories: The asset description metadata schema. Computers in Industry, 64(1), 1018.

The Getty Research Institute. (n.d.) Art \& Architecture Thesaurus Online. Retrieved from http://www.getty.edu/research/tools/vocabularies/aat/

Winget, M.A., \& Sampson, W.W. (2011). Game development documentation and institutional collection development policy. In Proceedings of the ACM/IEEE Joint Conference on Digital Libraries (pp. 29-38).

\section{Appendix}

\section{Interview Protocol}

Hi, I'm [name]. Thanks for agreeing to participate in our study. Today I'm going to ask you some questions about your video game preferences and habits. We want to know what you think about video games! Just to be clear, when we talk about video games, we mean everything from PC games, console games, online games, even games that you play on your smartphone or tablet. Our definition is very wide, and we don't want to leave anything out. If you're not sure if something you're thinking about is a "video game," feel free to ask. I'm going to be audio recording this interview just so we can remember what you said. The recording will be transcribed for analysis, but your name and any other identifying information will be removed.

Any questions before we begin? 
Before we dive into the questions about games, I'd like to ask you a few basic questions:

- In what year were you born?

- What is your profession?

- Do you identify with any particular ethnicity?

Now I'd like to ask you some questions about playing video games:

- What are your all-time favorite video games?

- Why are these games your favorite?

- What game-playing devices do you currently own?

- What systems/consoles/devices have you used in the past that you no longer use?

- Approximately how long have you been playing video games?

- How often do you play video games?

- How long do you usually play games in a single session?

- Of the time you spend playing video games, what percentage is spent playing alone versus playing with other people?

- Where do you usually play games?

- Why do you play video games?

- What percentage of your video game collection consists of physical games versus digital games?

- Between physical and digital games, which do you prefer and why?

- What percentage of your video game collection do you actively use?

[If applicable] Now I'd like to ask you some questions about physical video games:

- How many different physical video games do you play in an average week?

- Approximately how many physical video games do you currently own?

- Where do you usually acquire physical video games?

- What percentage of your physical video games did you acquire new vs. used?

- How often do you acquire physical video games?

- How do you learn about physical video games?

- How do you usually organize your physical video game collection?

- What do you do when you are no longer interested in a physical video game?

[If applicable] Now I'd like to ask you some questions about digital video games:

- How many different digital video games do you play in an average week?

- How many digital video games have you downloaded, streamed or accessed in the last month?

- From which sources do you usually acquire digital video games?

- How do you learn about new digital video games?

- How do you organize your digital video game collection?

- What do you do when you are no longer interested in a digital video game?

- What percentage of your digital collection is only available digitally (meaning the game was never physically published in cartridges, disc, etc.)?

Finally, I'd like to ask you some questions about how you find information about video games:

- Which websites or related resources do you visit to find more information about video games?

- What do you use these websites or related resources for?

- Which of the websites you mentioned do you find most useful when looking for information about games?

- $\quad$ Please tell us why you find that website most useful: 
- What information about games is most useful to you for games that you are currently playing and when you are looking for new games to play?

- Is there any other game-related information that is useful to you?

- Looking over the metadata elements, which of those elements do you think would be useful to you in an information system for video games (such as a database or website)?

- Are there any that you think would be not useful or problematic?

That's all the questions I have for you. Is there anything else you'd like to add?

\section{Relevant Questions from the Survey Questionnaire}

[Q21] What information about games is most useful to you for games that you are currently playing and when you are looking for new games to play?

\begin{tabular}{|c|c|c|}
\hline & $\begin{array}{l}\text { Useful for } \\
\text { games that you } \\
\text { are currently } \\
\text { playing }\end{array}$ & $\begin{array}{c}\text { Useful for } \\
\text { deciding which } \\
\text { new games to } \\
\text { play }\end{array}$ \\
\hline title & $\square$ & $\square$ \\
\hline alternative title & $\square$ & $\square$ \\
\hline edition (e.g., collector's edition, limited edition) & $\square$ & $\square$ \\
\hline format (e.g., cartridge, disc, born-digital) & $\square$ & $\square$ \\
\hline series (e.g., Final Fantasy, Halo) & $\square$ & $\square$ \\
\hline $\begin{array}{l}\text { franchise/universe (e.g., Final Fantasy Franchise including } \\
\text { Final Fantasy series, Crystal Chronicles, Kingdom Hearts, } \\
\text { etc. ) }\end{array}$ & $\square$ & $\square$ \\
\hline platform (e.g., PlayStation 3, Xbox 360, Nintendo 3DS) & $\square$ & $\square$ \\
\hline developer (e.g., Bungie for Halo) & $\square$ & $\square$ \\
\hline publisher (e.g., Microsoft Studios for Halo) & $\square$ & $\square$ \\
\hline distributor (e.g., Steam) & $\square$ & $\square$ \\
\hline special hardware (e.g., motion controller, gaming headset) & $\square$ & $\square$ \\
\hline $\begin{array}{l}\text { online capabilities (e.g., playing the game online, } \\
\text { downloading additional features) }\end{array}$ & $\square$ & $\square$ \\
\hline system requirements (e.g., memory, software version) & $\square$ & $\square$ \\
\hline $\begin{array}{l}\text { game credits (i.e., list of people who contributed to creating } \\
\text { the game) }\end{array}$ & $\square$ & $\square$ \\
\hline official website & $\square$ & $\square$ \\
\hline price/MSRP & $\square$ & $\square$ \\
\hline retail release date & $\square$ & $\square$ \\
\hline $\begin{array}{l}\text { packaging information (i.e., what is included in the game } \\
\text { package) }\end{array}$ & $\square$ & $\square$ \\
\hline number of players & $\square$ & $\square$ \\
\hline rating (i.e., ESRB) & $\square$ & $\square$ \\
\hline purpose (e.g., education, entertainment) & $\square$ & $\square$ \\
\hline customization options (e.g., for characters, levels) & $\square$ & $\square$ \\
\hline difficulty levels & $\square$ & $\square$ \\
\hline achievements/awards/trophies & $\square$ & $\square$ \\
\hline
\end{tabular}




\begin{tabular}{l|c|c}
\hline $\begin{array}{l}\text { region (e.g., North America (NTSC-U/C), Japan and Asia } \\
\text { (NTSC-J)) }\end{array}$ & $\square$ \\
\hline language & $\square$ & $\square$ \\
\hline $\begin{array}{l}\text { identifier (i.e., unique identifiers for the games such as } \\
\text { barcode, ASIN) }\end{array}$ & $\square$ \\
\hline box art/cover & $\square$ & $\square$ \\
\hline screenshots & $\square$ & $\square$ \\
\hline trailers & $\square$ & $\square$ \\
\hline gameplay videos & $\square$ & $\square$ \\
\hline genre/gameplay (e.g., Action, Strategy, Puzzle) & $\square$ & $\square$ \\
\hline $\begin{array}{l}\text { style (i.e., more detailed categories of genre such as } \\
\text { Platformer, Action RPG, Tower defense) }\end{array}$ & \\
\hline $\begin{array}{l}\text { plot/narrative (e.g., Protagonist explores world, Characters } \\
\text { prevent apocalypse) }\end{array}$ & $\square$ & $\square$ \\
\hline theme (e.g, fantasy-princess, supernatural-zombies) & $\square$ & $\square$ \\
\hline setting (e.g., nature, schools, modern) & $\square$ & $\square$ \\
\hline mood/affect (e.g., dark, humorous, quirky) & $\square$ & $\square$ \\
\hline $\begin{array}{l}\text { temporal aspect (e.g., real-time, time travel, time } \\
\text { manipulation) }\end{array}$ & $\square$ & $\square$ \\
\hline presentation (e.g., 2D, 3D, side-scrolling) & & $\square$ \\
\hline point of view (e.g., first person, third person) & $\square$ & $\square$ \\
\hline $\begin{array}{l}\text { references to historical events (e.g., World War II, The } \\
\text { American Civil War) }\end{array}$ & $\square$ & $\square$ \\
\hline type of ending (e.g., new game+, multiple endings) & $\square$ & $\square$ \\
\hline visual style (e.g., retro, anime/manga, realistic) & $\square$ \\
\hline
\end{tabular}

[Q22]Is there any other game-related information that is useful to you?

Please write your answer here:

\section{List of Sample Games}

\begin{tabular}{l|l|l}
\hline Game Title & Platform & Developer \\
\hline Agricola & iOS app (iPad) & Playdek, Inc. \\
\hline Bakery Story & iOS app (iPhone) & TeamLava \\
\hline BANG! [HD] the Official Video Game & iOS app (iPad) & SpinVector S.p.A. \\
\hline Barry's Bad Night & Flash-based & danthemilk \\
\hline Bioshock Infinite & Xbox 360 & Irrational Games \\
\hline Bubble Witch Saga & iOS app (iPhone) & King.com Limited \\
\hline Bubsy In: Claws Encounters of the & Super Nintendo & Accolade \\
Furred Kind & Entertainment System & Rockstar Vancouver \\
\hline Bully: Scholarship Edition & Xbox 360 & Treyarch \\
\hline Call of Duty: Black Ops II & Xbox 360 & King.com Limited \\
\hline Candy Crush Saga & iOS app (iPhone) & Konami \\
\hline Castlevania: Order of Ecclesia & Nintendo DS & USM \\
\hline Catan HD & iOS app (iPad) & Big Daddy's Creations \\
\hline Caylus & iOS app (iPad) &
\end{tabular}




\begin{tabular}{|c|c|c|}
\hline Champions of Norrath: Return to Arms & PlayStation 2 & Snowblind Studios \\
\hline $\begin{array}{l}\text { Commander Keen: Aliens Ate My } \\
\text { Babysitter! }\end{array}$ & PC DOS & iD Software Inc. \\
\hline Condemned: Criminal Origins & Xbox 360 & Monolith Productions, Inc. \\
\hline Dance Central & Xbox 360 & Harmonix \\
\hline Dead Space & Xbox 360 & EA Redwood Shores \\
\hline Jump Super Stars & Nintendo DS & Ganbarion \\
\hline Donkey Kong Country & Super Nintendo & Rare LTD \\
\hline Dots: A Game About Connecting & Android & Playdots, Inc. \\
\hline Dragon Age II & PC Windows & BioWare \\
\hline $\begin{array}{l}\text { Dragon Ball Z: Legend of the Super } \\
\text { Saiyan }\end{array}$ & $\begin{array}{l}\text { Super Nintendo } \\
\text { Entertainment System }\end{array}$ & Bandai \\
\hline DragonGem & Android & ITREEGAMER \\
\hline Digimon Adventure 02: D-Terminal & D-Terminal & Bandai \\
\hline Dungeons \& Dragons Online & PC download & Turbine, Inc. \\
\hline Eternal Darkness: Sanity's Requiem & Nintendo GameCube & Silicon Knights \\
\hline Fallout 3 & Xbox 360 & Bethesda \\
\hline $\begin{array}{l}\text { Final Fantasy Tactics: The War of the } \\
\text { Lions for iPad }\end{array}$ & iOS app (iPad) & Square Enix Inc. \\
\hline LINE Fluffy Diver & iOS (iPhone) & LINE Corporation \\
\hline $\begin{array}{l}\text { Gabriel Knight 3: Blood of the Sacred, } \\
\text { Blood of the Damned }\end{array}$ & PC Windows & Sierra Studios \\
\hline Ghost Trick: Phantom Detective & iOS app (iPad) & Capcom \\
\hline Grid Game & Flash-based & Mark James \\
\hline Inindo: Way of the Ninja & Super Nintendo & Koei \\
\hline InSpheration & Flash-based & Puzzle Lab \\
\hline Juniper's Knot & PC download & Dischan Media \\
\hline Kumo Lumo & iOS app (iPhone) & Chillingo \\
\hline Mario Teaches Typing 2 & PC Windows & Brainstorm \\
\hline Mass Effect 2 & Xbox 360 & Bioware \\
\hline Minesweeper Classic & Android & IT Benefit \\
\hline Neverwinter & PC download & Cryptic Studios \\
\hline $\begin{array}{l}\text { No One Lives Forever 2: A Spy in } \\
\text { H.A.R.M.'s Way }\end{array}$ & PC Windows & Monolith Productions, Inc. \\
\hline $\begin{array}{l}\text { Phoenix Wright: Ace Attorney Trilogy } \\
\text { HD }\end{array}$ & iOS app (iPad) & Capcom \\
\hline Physicus & PC Windows & $\begin{array}{l}\text { Ruske \& Pühretmaier } \\
\text { Edutainment GmbH }\end{array}$ \\
\hline Planetarian & iOS app (iPad) & VisualArts Co., Ltd. \\
\hline Plants vs. Zombies HD & iOS app (iPad) & PopCap \\
\hline Puyo Puyo Fever 2 & Nintendo DS & Sega \\
\hline Rayman Origins & PlayStation 3 & Ubisoft Montpellier Studios \\
\hline Reiner Knizia's Tigris \& Euphrates & iOS app (iPad) & Codito Development Inc. \\
\hline Resident Evil 6 & Xbox 360 & Capcom \\
\hline Robot Unicorn Attack & Flash-based & [adult swim] games \\
\hline The Sims FreePlay & Android & EA Swiss Sarl \\
\hline $1080^{\circ}$ Snowboarding & Nintendo 64 & Nintendo EAD \\
\hline
\end{tabular}




\begin{tabular}{l|l|l}
\hline Solitaire & Android & Ken Magic \\
\hline Spore & PC Windows & Maxis \\
\hline System Shock 2 & PC Windows & Irrational Games LLC \\
\hline The Elder Scrolls V: Skyrim & Xbox 360 & Bethesda \\
\hline The Journey to Wild Divine: The Passage & PC Windows & The Wild Divine Project \\
\hline The Legend of Zelda Skyward Sword & Wii & Nintendo EAD \\
\hline Tiny Farm & iOS app (iPhone) & Com2uS USA, Inc. \\
\hline Transformers: War for Cybertron & Xbox 360 & High Moon Studios \\
\hline Uncharted: Drake's Fortune & PlayStation 3 & Naughty Dog \\
\hline VidRhythm & iOS app (iPad) & Harmonix \\
\hline WhizzBall! & Flash-based & Discovery Kids \\
\hline Words With Friends Free & iOS app (iPhone) & Zynga Inc. \\
\hline
\end{tabular}

${ }^{1}$ http://library.stanford.edu/news/2013/03/stanford-libraries-preserves-historical-software-collectionfederal-agency

${ }^{2} \mathrm{http}: / /$ www.imls.gov/news/2013_ols_grant_announcement.aspx\#CA

${ }^{3} \mathrm{http}: / /$ blog.imls.gov/?p=4091

${ }^{4}$ The survey asked for feedback on a total of 43 elements from REC set version 1.2 in which the elements $<$ character types $>$, <character names $>$, and <controls $>$ were removed based on feedback from the collaborative review

${ }^{5}$ Nintendo Wi-Fi Connection service for Nintendo DS and Wii to end in May. https://www.nintendo.com/whatsnew/detail/vyWpoM6CBIe6FjW8NIY7bvzOrgBURhzw ${ }^{6} \mathrm{http}: / /$ wiki.teamfortress.com/wiki/Achievements

7 [M]: Mandatory, [R]: Repeatable 